\title{
Supramolecular structures constructed from three novel rare earth metal complexes
}

\author{
HUAZE DONG ${ }^{\mathrm{a}, *}$, XIAOJUN FENG $^{\mathrm{b}, *}, \mathrm{XIA} \mathrm{LIU}^{\mathrm{c}}, \mathrm{BIN}^{\mathrm{Z}} \mathrm{HENG}^{\mathrm{a}}, \mathrm{JIANHONG} \mathrm{BI}^{\mathrm{a}}$, YAN XUE$^{\mathrm{a}}$, \\ SHAOHUA GOU ${ }^{\mathrm{d}}$ and YANPING WANG ${ }^{\mathrm{a}}$ \\ ${ }^{a}$ Department of Chemistry and Chemical Engineering, Hefei Normal University, Hefei 230061, China \\ ${ }^{\mathrm{b}}$ Food and Drug Department, Qingyuan Polytechnic, Qingyuan 511510, P. R. China \\ ${ }^{\mathrm{c}}$ Department of City Science, The City Vocational College of Jiangsu, Nanjing 210017, China \\ ${ }^{\mathrm{d}}$ Department of Science and Technology, Jiangsu Open University, Nanjing 210036, China \\ e-mail: dapdong@163.com; xiaoche7207@126.com
}

MS received 02 August 2014; revised 18 December 2014; accepted 20 December 2014

\begin{abstract}
Three rare earth metal supramolecular complexes, $\left\{\left[\mathrm{Tb}\left(\boldsymbol{L}_{\mathbf{2}}\right)_{4}\right]\left(\mathrm{ClO}_{4}\right)_{3} \cdot 2 \mathrm{H}_{2} \mathrm{O}(\mathbf{1}),\left[\mathrm{Eu}\left(\boldsymbol{L}_{\mathbf{2}}\right)_{2}\left(\mathrm{H}_{2} \mathrm{O}\right)_{5}\right]\right.$ $\left(\mathrm{ClO}_{4}\right)_{3}(\mathbf{2})$ and $\left[\mathrm{Gd}\left(\mathrm{NO}_{3}\right)_{3}\left(\boldsymbol{L}_{\mathbf{2}}\right)_{2}\right] \cdot 2 \mathrm{CH}_{3} \mathrm{CH}_{2} \mathrm{OH}(\mathbf{3})\left(\boldsymbol{L}_{\mathbf{2}}=3\right.$-Dimethylamino-1-pyridin-2-yl-propenone), have been synthesized and characterized by elemental analysis, IR and single crystal X-ray diffraction. The crystal structure analysis reveals that the coordination numbers of three complexes (1-3) are 8, 9 and 10, respectively. Three complexes assembled into 3D frameworks based on $\mathrm{C}-\mathrm{H} \cdots \mathrm{O}, \mathrm{O}-\mathrm{H} \cdots \mathrm{O}$ hydrogen bond linkages.
\end{abstract}

Keywords. Rare earth metal complex; crystal structure; hydrogen bonds; 3D supramolecular structure.

\section{Introduction}

The self-assembly of supramolecules via non-covalent bonds is currently an interesting topic of research. Their diverse structures and stability have attracted the attention of chemists and biologists. ${ }^{1-6}$ In the selfassembling hydrogen bonding structures, $\mathrm{CH}-\pi$ and $\pi-\pi$ stacking play important roles in higher dimensional supramolecular framework construction. They are indispensable for architecture formation and can reinforce the structural stability with a wide range of potential applications in gas storage, sensor, catalysis, semiconductor, superconductor, optical switch and solar cell. Compared with other forces of interactions, the hydrogen bond has been considered as the most important interaction in supramolecular chemistry due to its relative strength, directionality and ability to provide a directing force in determining the molecular conformation and arrangement in solids. ${ }^{7-10}$ The design of a number of supramolecular frameworks with significantly different motifs, such as layers, ribbons, tubes, sheets and spheres, can be achieved through strong N$\mathrm{H} \cdots \mathrm{O}$ and $\mathrm{O}-\mathrm{H} \cdots \mathrm{O}$ hydrogen bonds. ${ }^{11,12}$ In addition, it is worthy to note that the weak $\mathrm{C}-\mathrm{H}$... O hydrogen bonds also play an important role in further stabilizing the 3-D network structures.

*For correspondence
In our previous work, we have reported several complexes derived from two ligand entities and transition metal salts ${ }^{13-17}$ (scheme 1). Herein, we describe three supramolecules of coordination compounds $\left\{\left[\operatorname{Tb}\left(\boldsymbol{L}_{\mathbf{2}}\right)_{4}\right]\right.$ $\left(\mathrm{ClO}_{4}\right)_{3}(\mathbf{1}), \quad\left[\mathrm{Eu}\left(\boldsymbol{L}_{\mathbf{2}}\right)_{2}\left(\mathrm{H}_{2} \mathrm{O}\right)_{5}\right]\left(\mathrm{ClO}_{4}\right)_{3}(\mathbf{2}), \quad\left[\mathrm{Gd}\left(\mathrm{NO}_{3}\right)_{3}\right.$ $\left.\left.\left(\boldsymbol{L}_{\mathbf{2}}\right)_{2}\right](\mathbf{3})\right\}$ from $\boldsymbol{L}_{\mathbf{2}}\left(\boldsymbol{L}_{\mathbf{2}}=3\right.$-Dimethylamino-1- pyridin2- yl-propenone), constructed by strong $\mathrm{O}-\mathrm{H} \cdots \mathrm{O}$ hydrogen bonds and weak $\mathrm{C}-\mathrm{H}$... O hydrogen bonds. These studies have advanced our understanding of hydrogen-bonding and interactions for the construction of structures with varied architecture.

\section{Experimental}

All reagents were of AR grade and used without purification. 3-(Dimethylamino) - 1-(pyridine-2-yl) prop-2en-1-one was prepared by similar procedure reported in the literature. ${ }^{17}$ Elemental analysis was measured on a Perkin-Elmer 1400C analyzer. Infrared spectra (4000$400 \mathrm{~cm}^{-1}$ ) were measured with a Bruker Vector 22 FT-IR spectrophotometer on $\mathrm{KBr}$ disks.

\subsection{Synthesis}

The same method reported in literature ${ }^{14}$ was used in the synthesis of 1-3 except the mole ratio between ligand $\boldsymbol{L}_{\mathbf{2}}$ and three rare earth metal salts $\left[\mathrm{Tb}\left(\mathrm{ClO}_{4}\right)_{3}\right.$, $\left.\mathrm{Eu}\left(\mathrm{ClO}_{4}\right)_{3}, \mathrm{Gd}\left(\mathrm{NO}_{3}\right)_{3}\right]$. A solution of the ligand $(0.1$ $\mathrm{mmol})$ and rare earth metal salt $(0.1 \mathrm{mmol})$ in $40 \mathrm{~mL}$ of 


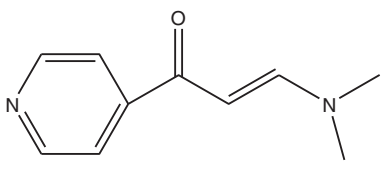

$L_{1}$

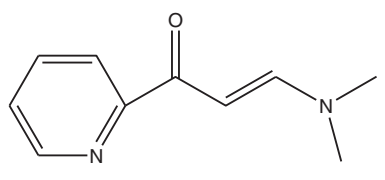

$L_{2}$
Scheme 1. The molecular structures of two ligands.

ethanol was refluxed for $2 \mathrm{~h}$, and then cooled to room temperature and filtered. Single crystals suitable for $\mathrm{X}$-ray analysis were grown from the mother solution by slow evaporation at room temperature in air.

1: Anal. calcd for $\mathrm{C}_{40} \mathrm{H}_{52} \mathrm{Cl}_{3} \mathrm{~N}_{8} \mathrm{O}_{18} \mathrm{~Tb}$ : C,40.10; $\mathrm{H}$, 4.37; N, 9.35\%. Found: C, 40.02; H, 4.46; $\mathrm{N}, 9.19 \%$. IR $\left(\mathrm{KBr}, \mathrm{cm}^{-1}\right): 3469(\mathrm{~m}), 1657(\mathrm{~m})$, 1606(m), 1518(m), 1467(m), 1386(s), 1221(w), 1086(s), 1024(w), 833(w).

2: Anal. calcd for $\mathrm{C}_{20} \mathrm{H}_{34} \mathrm{Cl}_{3} \mathrm{EuN}_{4} \mathrm{O}_{19}$ : C,26.91; $\mathrm{H}$, 3.84; N, 6.28\%. Found: C, 26.88; H, 3.87; $\mathrm{N}, 6.26 \%$. IR $\left(\mathrm{KBr}, \mathrm{cm}^{-1}\right): 3461(\mathrm{~m}), 1664(\mathrm{~m})$, 1613(m), 1526(m), 1467(m), 1380(s), 1232(w), 1102(s), 1026(w), 840(w).

3: Anal. calcd for $\mathrm{C}_{24} \mathrm{H}_{36} \mathrm{GdN}_{7} \mathrm{O}_{13}: \mathrm{C}, 36.59 ; \mathrm{H}$, 4.61; N, 12.45\%. Found: C, 36.62; H, 4.71; $\mathrm{N}, 12.18 \%$. IR $\left(\mathrm{KBr}, \mathrm{cm}^{-1}\right): 3470(\mathrm{~m}), 1652(\mathrm{~m})$, 1596(m), 1533(m), 1508(vs), 1467(m), 1393(s), 1294(s), 1228(w), 1021(w), 830(w), 819(w), 742(w).

\section{$2.2 X$-ray crystallography}

X-ray data for complexes 1-3 were collected on a Bruker SMART 1K CCD diffractometer at 293 $\mathrm{K}$ employing graphite-monochromatized $\mathrm{MoK} \alpha$ radiation $(\lambda=0.71073 \AA)$. The data were collected using SMART and reduced by the program SAINT. ${ }^{18}$ The structure was solved by the direct method and refined by full-matrix least squares fitting on ' $\mathrm{F}_{\mathrm{obs}}^{2}$ ' by SHELXTL-PC. ${ }^{19}$ All non-hydrogen atoms were refined with anisotropic thermal parameters. The $\mathrm{C}-\mathrm{H}$ hydrogen atoms were positioned geometrically and refined using a riding model with $d\left(\mathrm{CH}_{\text {aro }}\right)=0.95 \AA$, $U_{\text {iso }}=$ $1.2 U_{\text {eq }}(\mathrm{C})$ for aromatic and $0.98 \AA, U_{\text {iso }}=1.2 U_{\text {eq }}(\mathrm{C})$ for $\mathrm{CH}_{3}$. The $\mathrm{O}-\mathrm{H}$ hydrogen atoms were localized by difference Fourier maps and refined by fixing the bond lengths to $0.840(1) \AA$. The crystallographic data for complexes $\mathbf{1 - 3}$ are listed in table 1 .

\section{Results and Discussion}

\subsection{Synthesis and characterization}

All the complexes were prepared in 1:1 metal/ligand molar ratio. Infrared spectra of 1-3 display bands

Table 1. Crystallographic data and refinement parameters of complexes 1-3.

\begin{tabular}{|c|c|c|c|}
\hline complex & 1 & 2 & 3 \\
\hline Empirical formula & $\mathrm{C}_{40} \mathrm{H}_{52} \mathrm{Cl}_{3} \mathrm{~N}_{8} \mathrm{O}_{18} \mathrm{~Tb}$ & $\mathrm{C}_{20} \mathrm{H}_{34} \mathrm{Cl}_{3} \mathrm{EuN}_{4} \mathrm{O}_{19}$ & $\mathrm{C}_{24} \mathrm{H}_{36} \mathrm{GdN}_{7} \mathrm{O}_{13}$ \\
\hline Formula weight & 1198.18 & 892.82 & 787.85 \\
\hline Crystal size (mm) & $0.23 \times 0.25 \times 0.30$ & $0.29 \times 0.32 \times 0.34$ & $0.29 \times 0.30 \times 0.32$ \\
\hline Crystal system & monoclinic & monoclinic & monoclinic \\
\hline Space group & $P 22_{1} / c$ & $C 2 / c$ & $C 2 / c$ \\
\hline$a(\AA)$ & $16.1966(10)$ & $17.949(4)$ & $21.322(2)$ \\
\hline$b(\AA)$ & $21.4944(13)$ & $12.194(3)$ & $10.9876(11)$ \\
\hline$c(\AA)$ & $22.4537(10)$ & $17.427(4)$ & $16.3844(16)$ \\
\hline$\alpha\left[^{\circ}\right]$ & 950.00 & 90.00 & 90 \\
\hline$\beta\left[^{\circ}\right]$ & $128.901(3)$ & $116.301(4)$ & $121.020(2)$ \\
\hline$\gamma\left[^{\circ}\right]$ & 90.00 & 90.00 & 90 \\
\hline$V, \AA^{3}$ & $6083.4(6)$ & $3419.4(14)$ & $3289.6(6)$ \\
\hline $\mathrm{Z}$ & 4 & 4 & 4 \\
\hline$D_{\text {calcd }},\left(\mathrm{Mg} / \mathrm{m}^{3}\right)$ & 1.308 & 1.734 & 1.591 \\
\hline$\mu, \mathrm{mm}^{-1}$ & 1.359 & 2.150 & 2.086 \\
\hline$F(000)$ & 2432 & 1792 & 1588 \\
\hline $\begin{array}{l}\text { Ref. collected/unique } \\
\text { parameters }\end{array}$ & $32323 / 11873\left(R_{\text {int }}=0.065\right)$ & $8128 / 2957\left(R_{\mathrm{int}}=0.054\right)$ & $\begin{array}{c}8669 / 3225\left(R_{\text {int }}=0.054\right) \\
208\end{array}$ \\
\hline parameters & 631 & 272 & 208 \\
\hline$R 1^{\mathrm{a}}$ & 0.0728 & 0.0627 & 0.0549 \\
\hline$w R 2^{\mathrm{b}}$ & 0.1750 & 0.1657 & 0.1128 \\
\hline GOF & 1.01 & 1.11 & 1.04 \\
\hline Min. / max. $\rho\left(\mathrm{e} \cdot \AA^{-3}\right)$ & $-0.69 / 1.29$ & $-2.06 / 1.71$ & $-0.49 / 1.32$ \\
\hline
\end{tabular}

${ }^{\mathrm{a}} R 1=\sum|| F_{\mathrm{o}}|-| F_{\mathrm{c}}|| / \sum\left|F_{\mathrm{o}}\right|,{ }^{\mathrm{b}} w R 2=\left[\sum\left[w\left(F_{\mathrm{o}}^{2}-F_{\mathrm{c}}^{2}\right)^{2}\right] / \sum w\left(F_{\mathrm{o}}^{2}\right)^{2}\right]^{1 / 2}$ 
Table 2. Selected bond lengths $(\AA)$ and angles $\left(^{\circ}\right)$ of three complexes ${ }^{\mathrm{a}}$.

\begin{tabular}{|c|c|c|c|c|c|}
\hline \multicolumn{6}{|l|}{1} \\
\hline Tb1-O1 & $2.284(6)$ & $\mathrm{Tb} 1-\mathrm{O} 2$ & $2.313(8)$ & Tb1-O3 & $2.319(5)$ \\
\hline Tb1-O4 & $2.292(7)$ & Tb1-N1 & $2.521(5)$ & Tb1-N3 & $2.539(8)$ \\
\hline Tb1-N5 & $2.521(8)$ & Tb1-N7 & $2.538(9)$ & $\mathrm{O} 1-\mathrm{Tb} 1-\mathrm{O} 2$ & $130.7(2)$ \\
\hline O1-Tb1-O3 & $78.1(2)$ & O1-Tb1-O4 & $124.3(3)$ & O1-Tb1-N1 & $64.8(2)$ \\
\hline O1-Tb1-N3 & $80.9(3)$ & O1-Tb1-N5 & $142.8(2)$ & O1-Tb1-N7 & $81.4(3)$ \\
\hline O2-Tb1-O3 O9 & $124.5(2)$ & O2-Tb1-N7 & $140.1(3)$ & O3-Tb1-O4 & $130.6(2)$ \\
\hline O3-Tb1-N1 & $141.9(2)$ & O4-Tb1-N3 & $141.0(3)$ & N1-Tb1-N5 & $152.2(3)$ \\
\hline N1-Tb1-N7 & $102.2(3)$ & N3-Tb1-N7 & $154.8(3)$ & N5-Tb1-N7 & $88.9(3)$ \\
\hline N3-Tb1-N5 & $94.6(3)$ & N1-Tb1-N3 & $86.2(2)$ & O4-Tb1-N5 & $81.5(3)$ \\
\hline \multicolumn{6}{|l|}{2} \\
\hline Eu1-O1 & $2.315(5)$ & Eu1-O2 & $2.448(8)$ & Eu1-O3 & $2.388(10)$ \\
\hline Eu1-O4 & $2.541(12)$ & Eu1-N1 & $2.536(8)$ & Eu1-O1 ${ }^{\mathrm{I}}$ & $2.315(5)$ \\
\hline $\mathrm{Eu} 1-\mathrm{O} 2^{\mathrm{I}}$ & $2.448(8)$ & Eu1-O3 $3^{I}$ & $2.388(10)$ & Eu1-N1 ${ }^{\mathrm{I}}$ & $2.536(8)$ \\
\hline O1-Eu1-O2 & $132.3(2)$ & O1-Eu1-O3 & $76.1(3)$ & O1-Eu1-O4 & $115.90(18)$ \\
\hline $\mathrm{O} 1-\mathrm{Eu} 1-\mathrm{O} 1^{\mathrm{I}}$ & $128.2(3)$ & $\mathrm{O} 1-\mathrm{Eu} 1-\mathrm{O} 3^{\mathrm{I}}$ & $139.7(3)$ & $\mathrm{O} 2-\mathrm{Eu} 1-\mathrm{O} 2^{\mathrm{I}}$ & $138.5(3)$ \\
\hline O2-Eu1-N1 ${ }^{\mathrm{I}}$ & $133.4(3)$ & $\mathrm{O} 1^{\mathrm{I}}-\mathrm{Eu} 1-\mathrm{O} 3$ & $139.7(3)$ & O3-Eu1-N1 ${ }^{\mathrm{I}}$ & $153.4(3)$ \\
\hline O4-Eu1-N1 & $135.6(2)$ & $\mathrm{O} 1^{\mathrm{I}}-\mathrm{Eu} 1-\mathrm{O} 4$ & $115.90(18)$ & O4-Eu1-N1 ${ }^{\mathrm{I}}$ & $135.6(2)$ \\
\hline $\mathrm{O} 2^{\mathrm{I}}-\mathrm{Eu} 1-\mathrm{N} 1$ & $133.4(3)$ & O3 $3^{\mathrm{I}}-\mathrm{Eu} 1-\mathrm{N} 1$ & $153.4(3)$ & $\mathrm{O} 1^{\mathrm{I}}-\mathrm{Eu} 1-\mathrm{O} 2^{\mathrm{I}}$ & $132.3(2)$ \\
\hline \multicolumn{6}{|l|}{3} \\
\hline Gd1-O1 & $2.349(5)$ & $\mathrm{Gd} 1-\mathrm{O} 2$ & $2.548(6)$ & Gd1-O3 & $2.544(7)$ \\
\hline Gd1-O5 & $2.499(5)$ & Gd1-N1 & $2.552(4)$ & $\mathrm{Gd1-O} 1^{\mathrm{II}}$ & $2.349(5)$ \\
\hline $\mathrm{Gd} 1-\mathrm{O} 2^{\mathrm{II}}$ & $2.548(6)$ & $\mathrm{Gd} 1-\mathrm{O} 3^{\mathrm{II}}$ & $2.544(7)$ & $\mathrm{Gd} 1-\mathrm{O} 5^{\mathrm{II}}$ & $2.499(5)$ \\
\hline $\mathrm{Gd} 1-\mathrm{N} 1{ }^{\mathrm{II}}$ & $2.552(4)$ & $\mathrm{O} 1-\mathrm{Gd} 1-\mathrm{O} 2$ & $74.35(15)$ & O1-Gd1-O3 & $69.57(15)$ \\
\hline O1-Gd1-O5 & $137.50(19)$ & $\mathrm{O} 1-\mathrm{Gd} 1-\mathrm{N} 1$ & $64.35(17)$ & $\mathrm{O} 1-\mathrm{Gd} 1-\mathrm{O} 1^{\mathrm{II}}$ & $71.29(16)$ \\
\hline $\mathrm{O} 1-\mathrm{Gd} 1-\mathrm{O} 2^{\mathrm{II}}$ & $145.61(15)$ & O1-Gd1-O3 ${ }^{\mathrm{II}}$ & $116.65(15)$ & $\mathrm{O} 1-\mathrm{Gd} 1-\mathrm{O} 5^{\mathrm{II}}$ & $137.03(15)$ \\
\hline $\mathrm{O} 1^{\mathrm{II}}-\mathrm{Gd} 1-\mathrm{O} 2$ & $145.61(15)$ & $\mathrm{O} 2-\mathrm{Gd} 1-\mathrm{O} 2^{\mathrm{II}}$ & $140.03(15)$ & $\mathrm{O} 2-\mathrm{Gd} 1-\mathrm{O} 3^{\mathrm{II}}$ & $127.10(16)$ \\
\hline $\mathrm{O} 2-\mathrm{Gd} 1-\mathrm{N} 1 \mathrm{II}$ & $117.90(19)$ & O3-Gd1-N1 & $113.71(18)$ & $\mathrm{O} 1^{\mathrm{II}}-\mathrm{Gd} 1-\mathrm{O} 3$ & $116.65(15)$ \\
\hline $\mathrm{O} 2^{\mathrm{II}}-\mathrm{Gd} 1-\mathrm{O} 3$ & $127.10(16)$ & O3-Gd1-O3 ${ }^{\mathrm{II}}$ & $172.99(14)$ & O5-Gd1-N1 & $128.15(16)$ \\
\hline $\mathrm{O} 1^{\mathrm{II}}-\mathrm{Gd1}-\mathrm{O} 5$ & $137.03(15)$ & $\mathrm{O} 2^{\mathrm{II}}-\mathrm{Gd} 1-\mathrm{N} 1$ & $117.90(19)$ & N1-Gd1-N1 $1 \mathrm{II}$ & $149.74(17)$ \\
\hline $\mathrm{O} 1^{\mathrm{II}}-\mathrm{Gd} 1-\mathrm{O} 5^{\mathrm{II}}$ & $137.5(2)$ & $\mathrm{O} 3^{\mathrm{II}}-\mathrm{Gd} 1-\mathrm{N} 1^{\mathrm{II}}$ & $113.71(18)$ & $\mathrm{O} 5^{\mathrm{II}}-\mathrm{Gd} 1-\mathrm{N} 1^{\mathrm{II}}$ & $128.15(16)$ \\
\hline
\end{tabular}

a Symmetry transformations used to generate equivalent atoms: (I) $1-\mathrm{x}, \mathrm{y}, 1 / 2-\mathrm{z}$, (II) $1-\mathrm{x}, \mathrm{y}, 3 / 2-\mathrm{z}$,

Table 3. Selected hydrogen bond lengths $(\AA)$ and angles $\left(^{\circ}\right)$ of complexes $\mathbf{1 - 3}$.

\begin{tabular}{|c|c|c|c|c|c|}
\hline D-H...A & $\mathrm{D}-\mathrm{H}$ & H...A & D...A & $\angle \mathrm{DHA}$ & A \\
\hline \multicolumn{6}{|l|}{1} \\
\hline C12-H12...O12 & 0.930 & 2.570 & $3.49(3)$ & 173.0 & \multirow{7}{*}{$1+\mathrm{x}, \mathrm{y}, \mathrm{z}$} \\
\hline C20-H20A...O12 & 0.960 & 2.510 & $3.400(19)$ & 155.00 & \\
\hline С10- Н10С...O99 & 0.960 & 2.420 & $3.34(3)$ & 162.00 & \\
\hline C35-H35...O16 & 0.930 & 2.550 & $3.38(2)$ & 150.0 & \\
\hline C24- H24...O14 & 0.930 & 2.300 & $3.133(16)$ & 149.00 & \\
\hline С19- Н19С...O8 & 0.960 & 2.590 & $3.139(19)$ & 116.00 & \\
\hline C21- H21...O5 & 0.930 & 2.570 & $3.311(18)$ & 137.00 & \\
\hline \multicolumn{6}{|l|}{2} \\
\hline $\mathrm{O} 2-\mathrm{H} 2 \mathrm{C} \ldots \mathrm{O} 5^{\prime}$ & 0.8500 & 2.090 & $2.79(3)$ & 140.00 & \multirow{4}{*}{$\begin{array}{c}\mathrm{x}, \mathrm{y},-1+\mathrm{z} \\
1 / 2-\mathrm{x}, 1 / 2-\mathrm{y}, 1-\mathrm{z}\end{array}$} \\
\hline O2-H2D...O10 & 0.8500 & 2.540 & $3.11(2)$ & 125.00 & \\
\hline O2-H2D...O11 & 0.8500 & 2.05063 .00 & $2.879(17)$ & 163.00 & \\
\hline O3- H3С...O5' & 0.8500 & 2.580 & $3.31(3)$ & 144.0 & \\
\hline O3- H3D...O9 & 0.8500 & 2.160 & $2.90(2)$ & 145.0 & \multirow{4}{*}{$\begin{array}{c}1-\mathrm{x}, \mathrm{y}, 3 / 2-\mathrm{z} \\
1-\mathrm{x}, \mathrm{y}, 3 / 2-\mathrm{z} \\
/ 2+\mathrm{x}, 1 / 2-\mathrm{y},-1 / 2+\mathrm{z}\end{array}$} \\
\hline O3-H3D...O10 & 0.8500 & 2.580 & $3.38(3)$ & 157.0 & \\
\hline O3-H3D...O12 & 0.8500 & 1.930 & $2.75(3)$ & 162.0 & \\
\hline O4- H4C...O8' & 0.8500 & 1.990 & $2.83(5)$ & 169.0 & \\
\hline C1- H1...O7' & 0.9300 & 2.590 & $3.47(4)$ & 158.0 & \multirow{4}{*}{$\begin{array}{c}1 / 2-\mathrm{x}, 1 / 2+\mathrm{y}, 1 / 2-\mathrm{z} \\
1 / 2+\mathrm{x}, 1 / 2-\mathrm{y},-1 / 2+\mathrm{z} \\
1-\mathrm{x}, \mathrm{y}, 3 / 2-\mathrm{z} \\
1 / 2+\mathrm{x}, 1 / 2-\mathrm{y},-1 / 2+\mathrm{z}\end{array}$} \\
\hline C8- H8...O11 & 0.9300 & 2.500 & $3.292(19)$ & 142.0 & \\
\hline С9- H9А...О12 & 0.9600 & 2.540 & $3.15(3)$ & 121.0 & \\
\hline С9- Н9B...О8' & 0.9600 & 2.570 & $3.42(4)$ & 148.0 & \\
\hline \multicolumn{6}{|l|}{3} \\
\hline O7- H7...O3 & 0.8200 & 2.2400 & $3.046(14)$ & 169.00 & \multirow[b]{3}{*}{$3 / 2-x,-1 / 2+y, 3 / 2-z$} \\
\hline C8- H8...O1 & 0.9300 & 2.4100 & $2.767(8)$ & 103.00 & \\
\hline C12- H12C...O4 & 0.9600 & 2.5100 & $3.455(16)$ & 170.00 & \\
\hline
\end{tabular}


characteristic of the $\mathrm{O}-\mathrm{H}$ stretching vibration in the $3470-3450 \mathrm{~cm}^{-1}$ region. The absorption bands in the $1400-1670 \mathrm{~cm}^{-1}$ region are in accordance with the skeletal vibrations of ligand for these complexes. The strong bands of $\mathrm{ClO}_{4}^{-}$appear near $1100 \mathrm{~cm}^{-1}$ in the IR spectra of 1 and 2 . The bands of $\mathrm{NO}_{3}^{-}$appear near 1508, $1294,1021 \mathrm{~cm}^{-1}$ in the IR spectra of $\mathbf{3}$ (tables 2 and 3 ).

\subsection{Structural descriptions of complexes 1-3}

The complex 1, $\left\{\left[\mathrm{Tb}\left(\boldsymbol{L}_{\mathbf{2}}\right)_{4}\right]\left(\mathrm{ClO}_{4}\right)_{3} \cdot 2 \mathrm{H}_{2} \mathrm{O}\right.$, crystallizes in the monoclinic system, with space group $P 2_{1} / c$. The least unit of the complex consists of one central metal
$\mathrm{Tb}$ (III), four ligands, three free perchlorate counteranions and two lattice water molecules, as shown in figure 1a. The $\mathrm{Tb}$ centre is eight-coordinated by four oxygen atoms and four nitrogen atoms from four ligands with inverse square prism geometry. The bond distances between the terbium ion and oxygen atoms are from 2.284(6) $\AA$ to 2.319(5) $\AA$, while the Tb-N bonds range from 2.521(5) $\AA$ to 2.539(8) $\AA$.

For complex 1, independent mononuclear units are linked together via heteromeric hydrogen bonds, C12H12...O12, C20-H20A...O12 and C10- H10C...O9 to form a tiled chain. As shown in figure 1b, these hydrogen bonds are involved with oxygen atoms of one

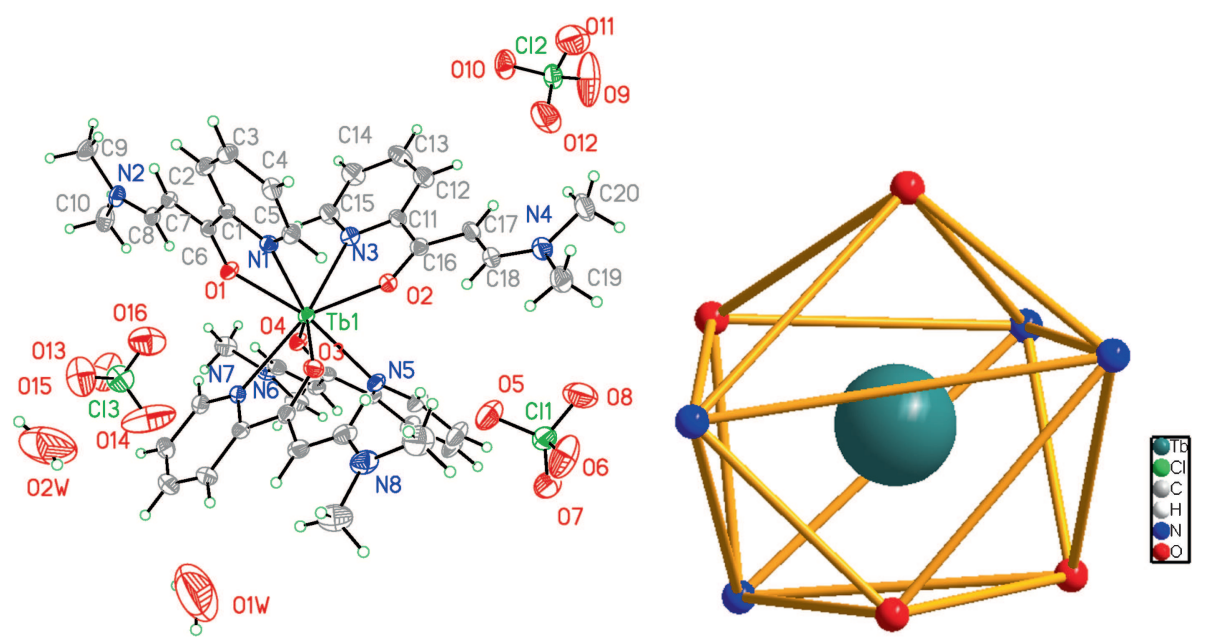

(a)

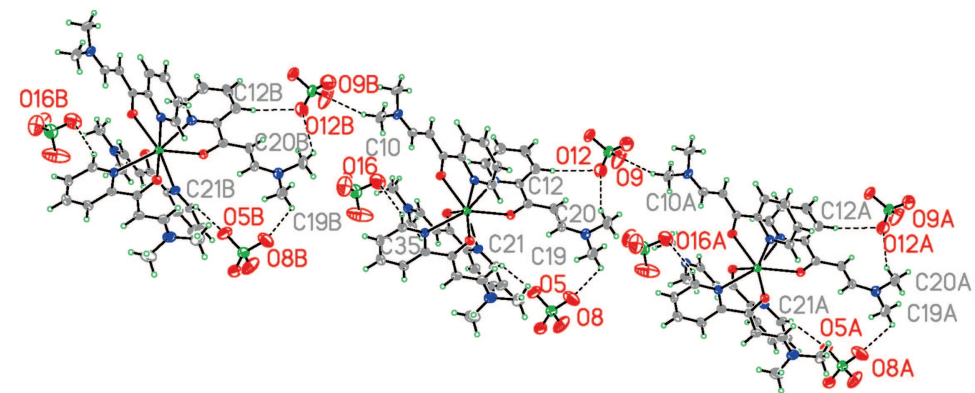

(b)

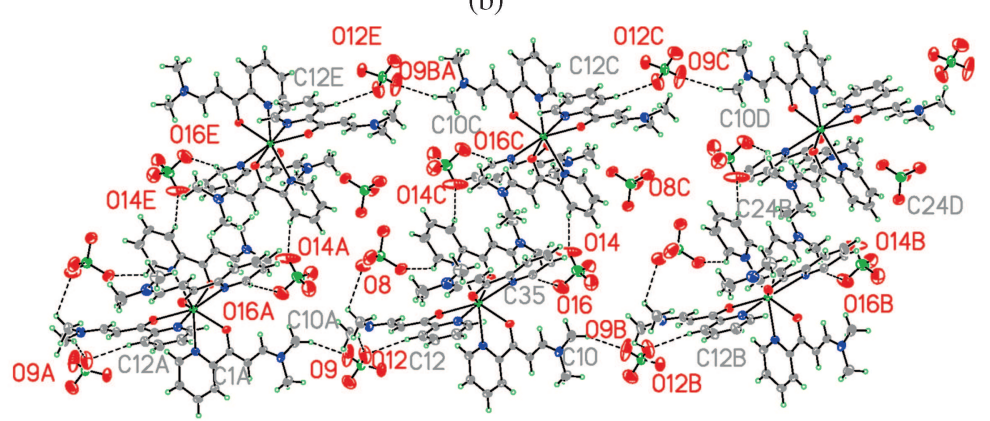

(c)

Figure 1. (a) Left: Perspective view of $\mathbf{1}$ with the atom-numbering scheme; Right: Geometry around the $\mathrm{Tb}(\mathrm{III})$ atom of $\mathbf{1}$. (b) One-dimensional chain structure in $\mathbf{1}$. (c) Two-dimensional planar structure in $\mathbf{1}$. 
perchlorate anion and the hydrogen of organic ligands. On the one hand, the resulting chains are spread through hydrogen bonds, C35-H35...O16 and C24- H24...O14, parallel to $b c$ plane to produce fluctuant 2D hydrogenbonded layers (figure 1c), which are formed by the oxygen atoms of second perchlorate and the hydrogen of organic ligands. The third perchlorate anion is connected to mononuclear units by the hydrogen-bonding.

The complex 2 crystallizes in monoclinic group $C 2 / c$ and displays a discrete mononuclear structure. The basic unit of the complex 2 consists of one central metal $\mathrm{Eu}(\mathrm{III})$, two ligands, three free perchlorate counteranions and five coordinated water molecules. Figure 2 a shows a perspective view of the molecular structure with atoms labelling.

As depicted in figure $2 \mathrm{a}$, the $\mathrm{Eu}(\mathrm{III})$ centre in $\mathbf{2}$ is nine-coordinated by two $\mathrm{N}$ and seven $\mathrm{O}$ atoms from two ligands and five water molecules with a distorted monocapped square antiprism. The bond distances between the Europium ion and oxygen vary from 2.315(7) $\AA$ to 2.448(8) $\AA$, which are slightly longer than the $\mathrm{Tb}$ $\mathrm{O}$ bond lengths, on the other hand the Eu-N bonds are 2.536(8) $\AA$ and similar to Tb-N bonds.

As shown in figure $2 b$, independent mononuclear units are linked together via heteromeric hydrogen bonds, C1-H1...O7', and O4- H4C...O8' to form a zigzag chain along $c$ axis. On the other hand, the independent units are linked together via classic hydrogen bonds between the coordination water molecules and perchlorate counter-anions, O2-H2D...O11, O3H3D...O9, O3- H3D...O10 and O3- H3D...O12 to form a chain along $b$ axis (figure $2 \mathrm{c}$ ). The above two kinds of hydrogen bonds are interwoven with each other to produce fluctuant 2D hydrogen-bonded layers parallel to $b c$ plane (figure $2 \mathrm{~d}$ ). Meanwhile the above planes are connected through hydrogen bonds, C8-H8...O11, C9H9A...O12 and C9- H9B...O8', to form 3D hydrogenbonding network.

Treatment of $\mathrm{L}_{1}$ with $\mathrm{Gd}\left(\mathrm{NO}_{3}\right)_{3}$ generates complex 3. Similarly with complex $\mathbf{2}$, complex $\mathbf{3}$ crystallizes in the monoclinic space group $C 2 / c$, consisting of one Gadolinium(III) ion, two ligands, three coordinated nitrates and two free ethanol molecules (figure 3a). The coordination geometry around the $\mathrm{Gd}$ (III) ion is a distorted double-capped dodecahedron composed of two $\mathrm{N}$ atoms and two $\mathrm{O}$ atoms from two ligands and six $\mathrm{O}$ atoms from three nitrates. The average Gd-O bond lengths are $2.485 \AA$, which are slightly longer than the $\mathrm{Tb}-\mathrm{O}$ bond lengths or Eu-O bond lengths.
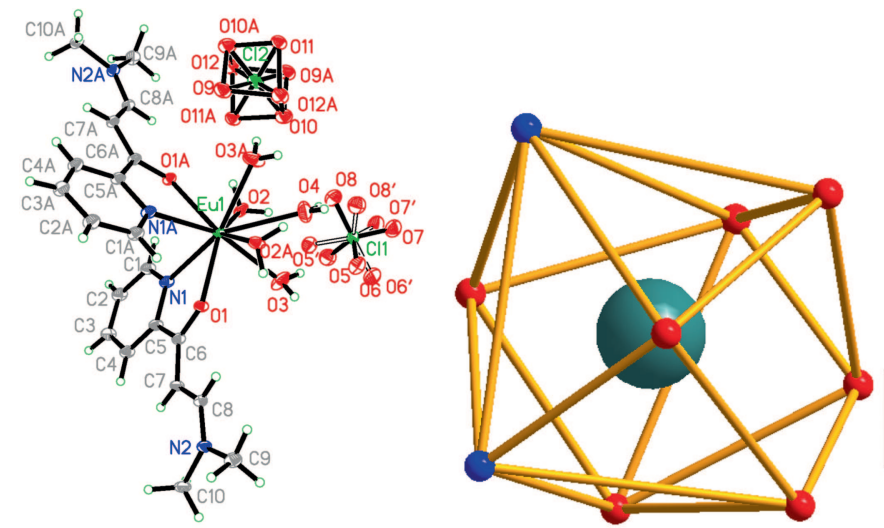

(a)

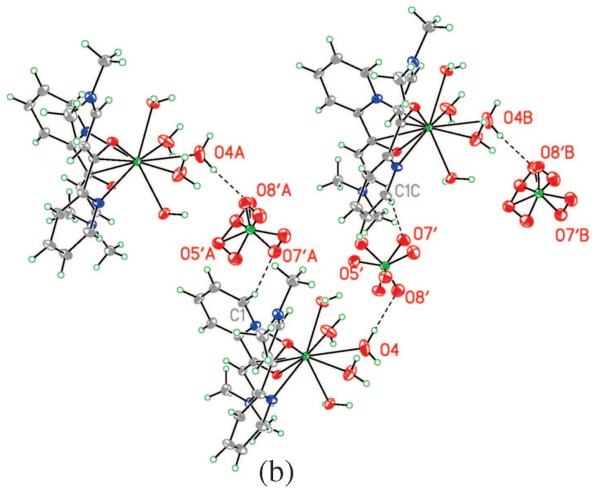

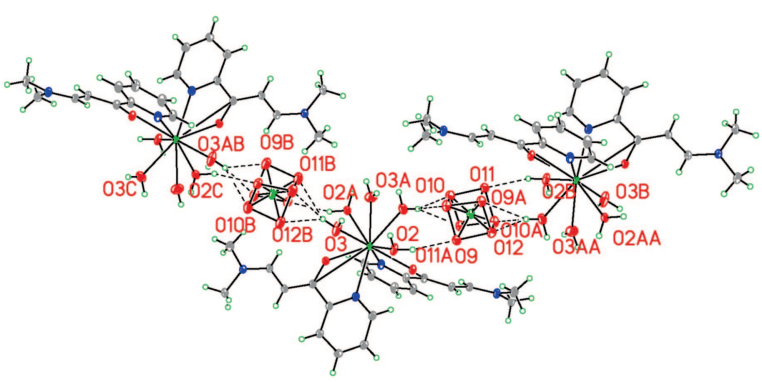

(c)

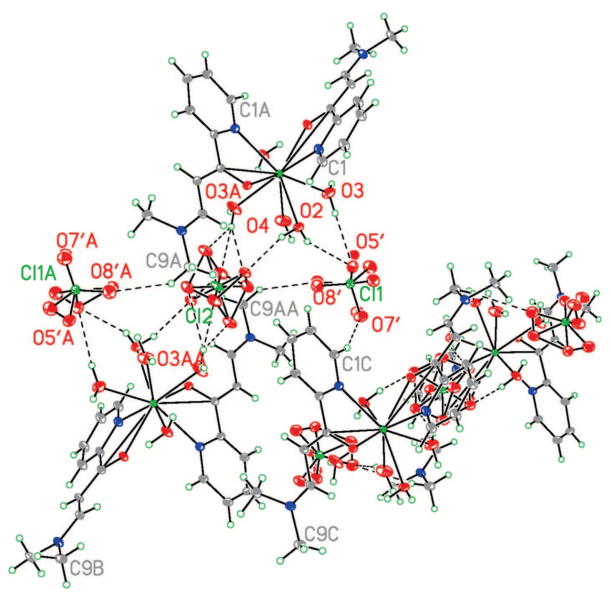

(d)

Figure 2. (a) Left: Perspective view of $\mathbf{2}$ with the atom-numbering scheme; Right: Geometry around the Eu(III) atom of 2. (b) Zig-zag chain structure in 2. (c) One-dimensional chain in 2. (d) Two-dimensional planar structure in 2. 

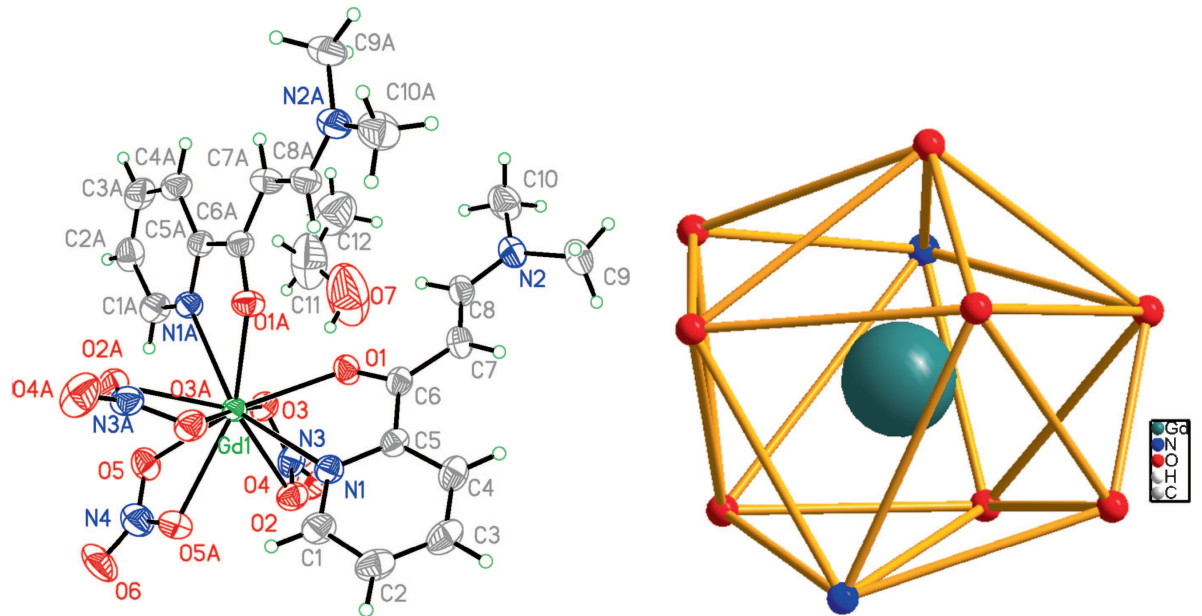

(a)

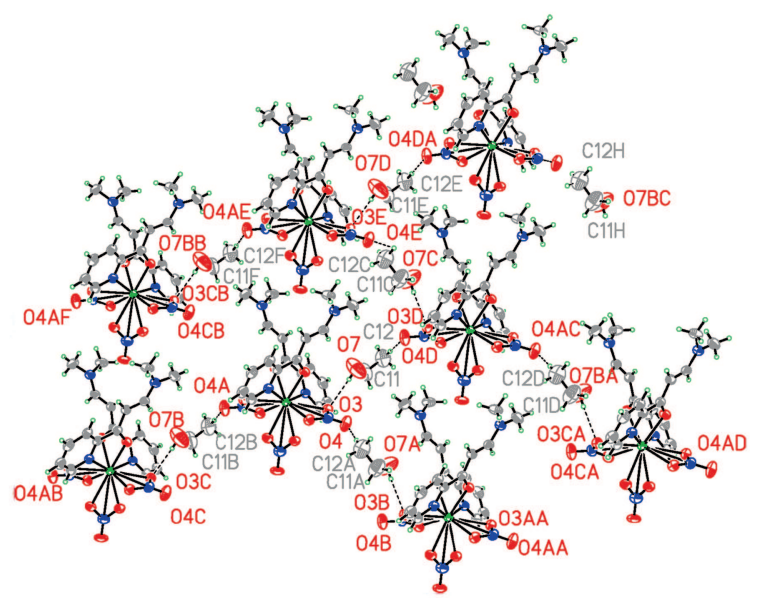

(b)

Figure 3. (a) Left: Perspective view of $\mathbf{3}$ with the atom-numbering scheme; Right: Geometry around the Gd(III) atom of $\mathbf{3}$. (b) Two-dimensional planar structure in $\mathbf{3}$.

It's interesting to note that the free ethanol molecules play an important role in the crystal structure, acting as hydrogen-bonding donors $(\mathrm{C} 12-\mathrm{H} 12 \mathrm{C} \cdots \mathrm{O} 4$ and O7-H7...O3 (figure 3b)), to connect the surrounding monocular units and form an undulating twodimensional plane.

\section{Conclusion}

Three rare earth metal supramolecular complexes, $\left\{\left[\mathrm{Tb}\left(\boldsymbol{L}_{\mathbf{2}}\right)_{4}\right]\left(\mathrm{ClO}_{4}\right)_{3} \cdot 2 \mathrm{H}_{2} \mathrm{O}(\mathbf{1}), \quad\left[\mathrm{Eu}\left(\boldsymbol{L}_{\mathbf{2}}\right)_{2}\left(\mathrm{H}_{2} \mathrm{O}\right)_{5}\right]\left(\mathrm{ClO}_{4}\right)_{3}\right.$ (2) and $\left[\mathrm{Gd}\left(\mathrm{NO}_{3}\right)_{3}\left(\boldsymbol{L}_{\mathbf{2}}\right)_{2}\right] \cdot 2 \mathrm{CH}_{3} \mathrm{CH}_{2} \mathrm{OH}(\mathbf{3})$, have been synthesized and characterized. The crystal structure analysis reveals that the ligand acts as $\mathrm{N}^{\wedge} \mathrm{O}$ chelation and the coordination numbers of three complexes (1-3) are 8, 9 and 10, respectively. The most common coordination numbers of rare earth complexes are 8 or 9. While some rare earth complexes with a coordination numbers of 11 or 12 often contain $\mathrm{NO}_{3}^{-}$as ligand, because $\mathrm{NO}_{3}^{-}$anion is small in size and low charge (small repulsion), it can also provide two coordination numbers in the formation of complexes. ${ }^{20,21}$ Because of the lanthanide contraction, ionic radius of $\mathrm{Eu}$ (94.7pm), Gd (93.8pm), Tb (92.3pm) decreases; hence, coordination numbers of complexes $\mathbf{1}$ and $\mathbf{2}$ are 8 or 9 , while the coordination number of complex 3, containing $\mathrm{NO}_{3}^{-}$with $\mathrm{O}^{\wedge} \mathrm{O}$ chelation, is 10 . In addition, the free perchlorates in complexes $\mathbf{1}$ and $\mathbf{2}$ take part in hydrogen-bonding to connect near units while the nitrates in complex 3 not only adopts the $\mathrm{O}^{\wedge} \mathrm{O}$ chelation but also act as hydrogen bond acceptor. These complexes assembled into 3D hydrogen-bonding frameworks based on C-H. . O and O-H. . O hydrogen bond linkages.

\section{Supplementary Information}

Crystallographic data for the structural analysis have been deposited at the Cambridge Crystallographic Data Center with CCDC deposition numbers 1016118- 
1016120 for the complexes. Copies of this information may be obtained free of charge via www.ccdc.cam.ac. uk/datarequest.cif.

\section{Acknowledgements}

The authors are indebted to the National Natural Science Foundation of China (No. 21101053) for financial support. This work is also supported by the Natural science fund for colleges and universities in Jiangsu Province (13KJB150009), Natural Science Foundation of Anhui Province Science Research Projects (1308085MB23, 1408085MB30), Foundation for scholar of Hefei Normal University (2014rcjj03, 2014136kjc06), Foundation of Educational Committee of Anhui Province (KJ2014A205, KJ2012Z327).

\section{References}

1. Janusz L, Janusz Z, Iwona J and Maciej D 2005 Coord. Chem. Rev. 119195

2. Sauvage J P 1999 In Transition Metals in Supramolecular Chemistry (Perspectives in Supramolecular Chemistry) (London: Wiley)

3. Stijn F M, Van D, Seda C, Alan E R and Roeland J M N 2014 Chem. Soc. Rev. 4399

4. Louis A and Pablo B 2013 Chem. Soc. Rev. 423261

5. Moulton B and Zaworotko M J 2001 Chem. Rev. 101 1629
6. Yang G P, Hou L, Luan X J, Wu B and Wang Y Y 2012 Chem. Soc. Rev. 416992

7. Beatty A M 2003 Coord. Chem. Rev. 246131

8. Satoshi D, Tomoyo S and Akikazu M 2008 Macromolecules 416055

9. Katarzyna P G, Adam R, Paweł $Ł$, Adam P, Czesław P, Bożena H and Maria P M 2013 Cryst. Eng. Comm. 15 1950

10. Komala P, Jonathan A K, Thomas M and Thorfinnur G 2013 Cryst. Eng. Comm. 151421

11. Wang C C, Yeh C T, Cheng Y T, Chen I H, Lee G H, Shih W J, Sheu H S and Fedorov V E 2012 Cryst. Eng. Comm. 144637

12. Saul H L, Jamie L M, Hyunsoo P, Alexander J C, Saman G, Paul G, Tom L, Johannes S M, Stephen J B, Mark T F T, Jinhee K, Myung-Hwan W and John A S 2013 Chem. Commun. 49499

13. Dong H Z, Bi W T and Wang H F 2009 Asian J. Chem. 215603

14. Chu Z L 2009 Acta Crystallogr., Sect. E 6585

15. Hu D H 2010 Acta Crystallogr., Sect. E 66709

16. Chu Z L and Dong H Z 2010 Asian J. Chem. 22629

17. Dong H Z, Chu Z L and Hu N L 2009 Acta Cryst. Sect. E $65 \mathrm{~m} 358$

18. Simens, SAINT Version 4 Software Reference Manual (Siemens Analytical X-ray Systems, Inc.) Madison: WI (1996)

19. Simens, SHELXTL Version 5 Reference Manual (Siemens Analytical X-ray Systems, Inc.) Madison: WI (1996)

20. Ren J Q and Xu G X 1986 Chem. J. Chinese U. 5 441

21. Huang C L, Yi T, Xu G X, Zhou J J and Xiao J F 1990 Univ. Chem. 55 